Revista Destaques Acadêmicos, Lajeado, v. 12, n. 4, 2020. ISSN 2176-3070

DOI: http://dx.doi.org/10.22410/issn.2176-3070.v12i4a2020.2754

http://www.univates.br/revistas

\title{
ESTUDO DE PROPOSTAS PARA UM SISTEMA DE TRAÇÃO 4X4 EM UM VEÍCULO DO TIPO BAJA SAE
}

\author{
Eduardo Zotti ${ }^{1}$, Misael David Hattge Lenz ${ }^{2}$, Ricson Rocha de Souza ${ }^{3}$
}

Resumo: O presente artigo refere-se a um estudo de propostas para um sistema de tração $4 \times 4$ em um veículo off-road de competição do tipo BAJA SAE. Assim, propõe-se uma análise comparativa com base em alguns critérios pré-estabelecidos e em alguns modelos existentes no mercado de sistemas de tração AWD (all-wheel drive) e 4WD (4-wheel drive). Nas aplicações automotivas, em especial do tipo off-road, sistemas de tração integral, que permitam a aplicação de energia e controle em todas as rodas do veículo, são de relevante importância para a experiência e segurança de utilização do piloto, através da maior estabilidade proporcionada e consequente capacidade de transposição de obstáculos. Diante deste contexto, neste trabalho, foram analisadas quatro propostas distintas para a construção de um sistema de tração integral (AWD e $4 \mathrm{WD}$ ), para um veículo Baja SAE (Society of Automotive Engineers), levando em conta aspectos relacionados às características funcionais e custos de fabricação, bem como facilidade de implementação e manutenção em situações de campo. É importante frisar que o estudo não envolve o dimensionamento do sistema, mas sim uma seleção prévia de componentes para levantamento de alterações necessárias no veículo para a implantação de um sistema de tração $4 \times 4$. Os projetos das propostas foram realizados em software SolidWorks e, como resultado das condições de seleção através de uma matriz de decisão, foi escolhida a proposta de um diferencial dianteiro, com modificação na caixa de redução, alcançando a pontuação pela matriz de decisão de 8,2 pontos, sendo essa a adequação com maior potencial de implantação em um veículo BAJA SAE.

Palavras-chave: Tração AWD e 4WD, Transmissão Baja 4x4, Diferencial Veículo Baja, Mini Baja.

1 Graduando do Curso de Engenharia Mecânica na Universidade do Vale do Taquari - Univates. eduardo.zotti@universo.univates.br

2 Graduando do Curso de Engenharia Mecânica na Universidade do Vale do Taquari - Univates. misael.lenz@universo.univates.br

3 Docente do Curso de Engenharia Mecânica na Universidade do Vale do Taquari - Univates. ricson.souza@univates.br 


\section{INTRODUÇÃO}

O Baja SAE é um projeto desenvolvido por estudantes de Engenharia que visa a aplicação de conceitos teóricos adquiridos em sala de aula com o intuito de projetar um veículo off-road de competição, além disso, prepara os alunos para o mercado de trabalho. O projeto Baja SAE foi concebido na Universidade da Carolina do Sul, Estados Unidos, e a primeira competição ocorreu em 1976. No Brasil, sua existência data de 1997, com a participação de dezenas de equipes, vinculadas às suas Instituições de Ensino Superior, nas regiões Sul, Sudeste e Nordeste (SAE NACIONAL, 2021).

Com a alta solicitação de eficiência dinâmica durante provas em competições realizadas pela Baja SAE, a implementação de um sistema com tração nas quatro rodas do veículo Baja caracteriza-se como uma solução mais eficiente, permitindo ao mesmo uma transposição mais fácil dos obstáculos. A tração poderá ser adicionada ao veículo com diferentes características para a mesma finalidade, onde pode ser implementado um sistema de tração integral, ao qual o veículo receberá constantemente torque nas quatro rodas ou um sistema de tração $4 \times 4$, sendo este mantido apenas nas rodas traseiras com o torque em tempo integral, sendo as demais acionadas por um mecanismo, quando se fizer necessária a utilização do sistema.

A Equipe Baja Univates Team tem no projeto de seu veículo o torque transmitido para as duas rodas traseiras, contudo, em provas dinâmicas durante as competições da Baja SAE, o veículo em algumas transposições de obstáculos têm dificuldades devido ao fato das rodas traseiras não ficarem em contato diretamente com o solo. Para sanar esse problema, e atender aos possíveis requisitos futuros da BAJA SAE, a equipe busca implementar um sistema de tração nas quatro rodas do veículo, onde um diferencial aplicado no eixo dianteiro do veículo será responsável por essa transmissão de torque e consequentemente auxílio na transposição de obstáculos.

O diferencial é um agrupamento de engrenagens no powertrain de um veículo, situado entre a caixa de transmissão e as rodas. O diferencial tem duas características que se destacam: trabalha como uma caixa de redução, quando o conjunto é projetado para tal, e possibilita a atuação das rodas em diferentes velocidades ao transpor uma curva ou obstáculos (GRAHAM, 1993).

O diferencial é composto por um conjunto de engrenagens denominadas coroa e pinhão e satélites e planetárias, além dos semi-eixos. A Figura 1 apresenta os componentes em um diferencial. 
Figura 1 - Componentes presente em um diferencial.

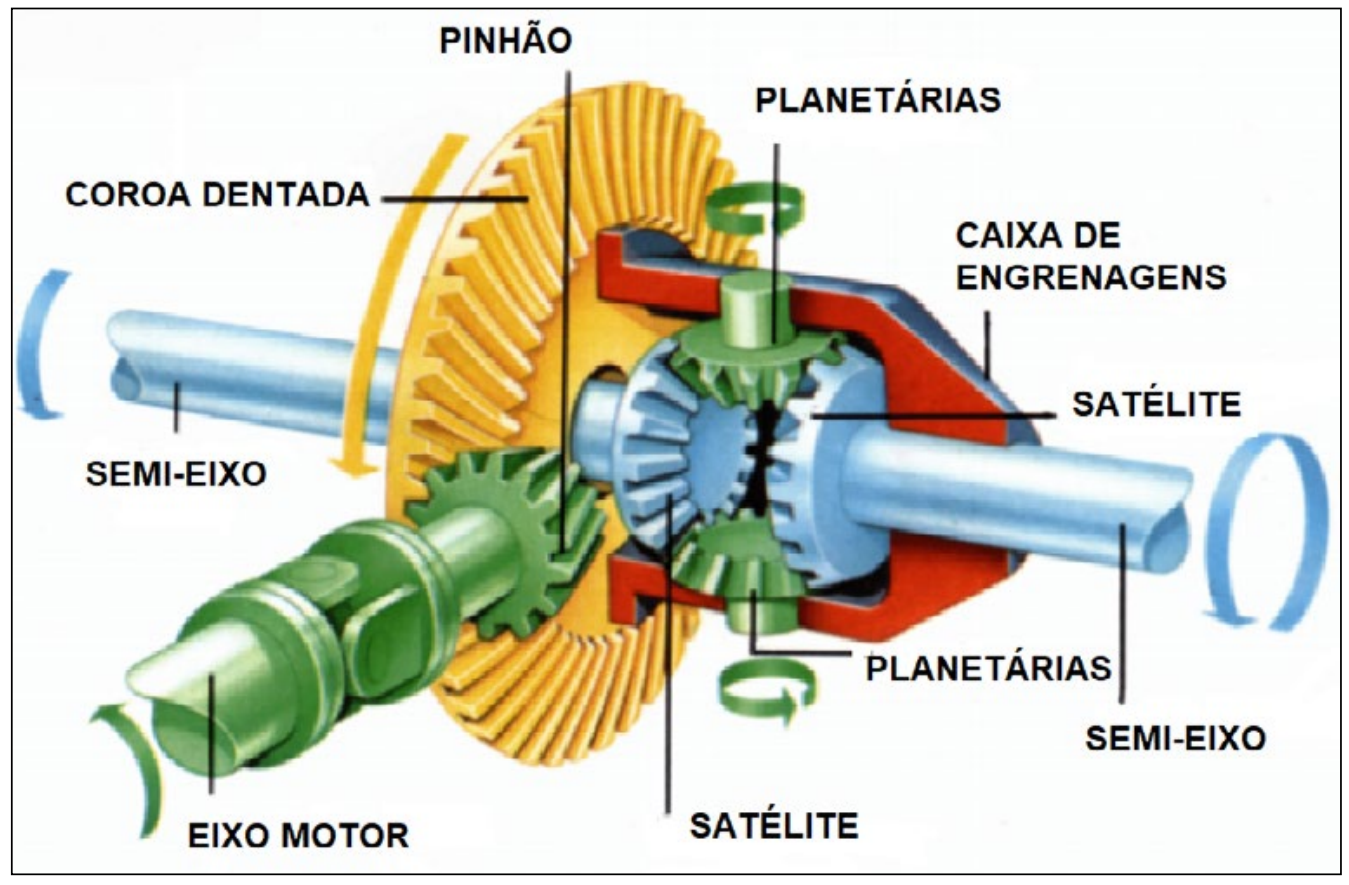

Fonte: Adaptado de Grewal (2011, pg. 2).

\section{DESENVOLVIMENTO}

Primeiramente, foram elaboradas quatro propostas, com o auxílio de um software CAD (Computer Aided Manufacturing), SolidWorks, versão 2020 sp2.0, e tendo em vista estudos realizados por diversos profissionais e estudantes da área, foi elaborado em seguida, uma matriz de decisão, para que assim realizar a escolha da proposta que fique mais assertiva dentro dos parâmetros pré-estabelecidos. Esta construção é expressa junto ao Figura 2 que resume o processo realizado para a seleção do tipo transmissão $4 \times 4$. 
Figura 2 - Resumo de etapas para seleção do sistema de transmissão 4x4.

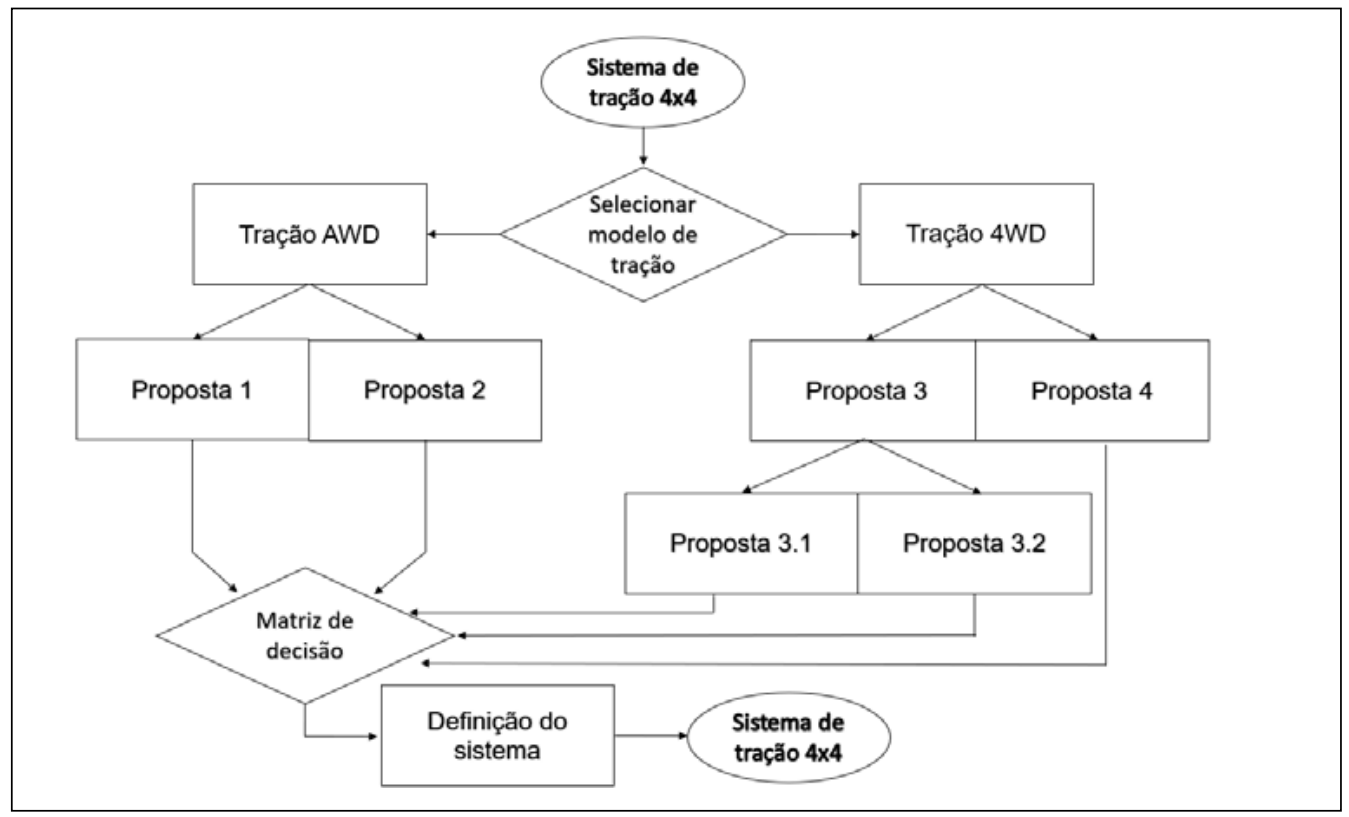

Fonte: Dos Autores (2020).

Sobral (2015), que desenvolveu um diferencial bloqueável para o sistema de powertrain para um veículo BAJA SAE. Já Singh (2008) propôs uma automatização no travamento das rodas, quando as mesmas não corresponderem corretamente ao funcionamento durante a realização de curvas.

Veeranjaneyulu e Babu (2012), viabilizaram a utilização da liga de alumínio 7475-T761, através de simulações e cálculos efetuados para a construção de conjuntos de diferenciais. Bergoli (2019), apresentou uma solução de componentes de veículos produzidos por montadoras com produção seriada, que passou por pequenas alterações e obteve um resultado satisfatório, para as tensões aplicadas em um diferencial de um veículo da marca Ford, modelo Ka, ano 2007, no mínimo duas vezes menores do que o limite de resistência a fadiga do material para ser aplicado em um veículo do tipo Mini BAJA SAE, conforme apresentado na Figura 3. 
Figura 3 - Resultados dos testes de tensão de impacto, torque e cisalhamento dos principais componentes aplicados em um diferencial de um veículo Ford Ka.

\begin{tabular}{|c|c|c|c|c|}
\hline \multicolumn{5}{|c|}{ Resultados engrenagens aplicadas ao Ford Ka } \\
\hline & $\begin{array}{c}\text { Tensão de von } \\
\text { Mices (Mpa) }\end{array}$ & $\begin{array}{c}\text { Fs } \\
\text { Fadiga }\end{array}$ & $\begin{array}{c}\text { Tensão de impacto } \\
\text { (Mpa) }\end{array}$ & Fs Impacto \\
\hline $\begin{array}{l}\text { Engrenagem } \\
\text { planetária }\end{array}$ & 907 & 0,41 & 1814 & 0,41 \\
\hline $\begin{array}{l}\text { Engrenagem } \\
\text { satélite }\end{array}$ & 778 & 0,48 & 1556 & 0,48 \\
\hline \multicolumn{5}{|c|}{ Resultados engrenagens aplicadas ao Baja } \\
\hline & $\begin{array}{c}\text { Tensão de von } \\
\text { Mices (Mpa) }\end{array}$ & $\begin{array}{c}\text { Fs } \\
\text { Fadiga }\end{array}$ & $\begin{array}{c}\text { Tensão de torque } \\
\text { integral (Mpa) }\end{array}$ & $\begin{array}{c}\text { Fs torque } \\
\text { integral }\end{array}$ \\
\hline $\begin{array}{c}\text { Engrenagem } \\
\text { planetária }\end{array}$ & 188 & 2 & 376 & 1,02 \\
\hline $\begin{array}{l}\text { Engrenagem } \\
\text { satélite }\end{array}$ & 161 & 2,3 & 323 & 1,2 \\
\hline \multicolumn{5}{|c|}{ Resultados pinos aplicados ao Ford Ka e Baja } \\
\hline & \multicolumn{2}{|c|}{ Ford Ka } & \multicolumn{2}{|l|}{ Baja } \\
\hline & $\begin{array}{c}\text { Tensão } \\
\text { cisalhamento } \\
\text { (Mpa) }\end{array}$ & Fs & $\begin{array}{c}\text { Tensão de } \\
\text { cisalhamento (Mpa) }\end{array}$ & Fs \\
\hline Pino original & 492 & 2,66 & 101 & 12,7 \\
\hline Pio secundário & - & - & 175 & 7,4 \\
\hline
\end{tabular}

Fonte: Adaptado de Bergoli (2019, pg. 37).

Em função dos bons resultados apontado por Bergoli (2019), onde as tensões de cisalhamento aplicada para solicitações de um veículo BAJA SAE ficaram aproximadamente 5 vezes menor em comparação ao que é solicitado no mesmo componente de um veículo de passeio. As tensões de fadiga e torque integral nas engrenagens satélites e planetárias (principais componentes de um diferencial) resultaram em um fator de segurança de aproximadamente 2 e 1,02 respectivamente em comparação aos resultados obtidos nos mesmos componentes aplicados em um veículo de passeio, com adequações oriundas de peças produzidas em série por empresas de renome, o estudo apresenta, da mesma forma, propostas com adequações advindas de peças em produção de larga escala, visando aquisição de baixo custo e facilidade para encontrar peças de reposição.

Após a apresentação de cada proposta, foi elaborada uma matriz de decisão e com base nos critérios de custo, manutenção, adaptação, construção e prova, foi então apontado os pesos e, consequentemente, selecionada a proposta mais adequada para a utilização em um veículo do tipo BAJA SAE. 
É importante frisar que para a realização deste estudo foi necessária uma adequação do projeto mecânico desenvolvido previamente para um veículo BAJA SAE, que não contemplava na proposta um sistema de tração do tipo $4 \times 4$. Desta forma, as quatro propostas de alteração são apresentadas nas figuras 4 a 8 , sendo que duas propostas, 1 e 2, correspondem a um sistema AWD e duas, 3 e 4, de sistema $4 \mathrm{WD}$, visando aplicação em um veículo do tipo BAJA SAE.

\subsection{PROPOSTA 1}

Buscou-se analisar a aplicação de dois diferenciais no veículo, com um sistema de tração AWD, onde a caixa de redução não sofre mudanças em sua confecção, apenas realocada dentro do travamento traseiro das barras (FAB up/ mid/low $)$ de cor verde, representado na Figura 4. Contudo, a construção desse mesmo travamento traseiro das barras $\left(\mathrm{FAB}_{\text {up } / \mathrm{mid} / \mathrm{low}}\right)$ deve ser adequado, a fim de ser possível inserir mais um componente, um diferencial traseiro. $\mathrm{Na}$ parte frontal do veículo, onde se encontra entre as barras $\left(\mathrm{FAB}_{\text {low }} / \mathrm{FLC} / \mathrm{SIM}\right)$ na cor azul, representado na Figura 4, é aplicado um segundo diferencial, onde o mesmo é acionado mecanicamente por eixo.

Figura 4 - Projeto estrutural de um veículo Baja Sae, desenvolvido com o software Solidworks. Cores azul e verde, representam as barras $F_{A B}$ e $F_{\text {up }} B_{\text {low }}$ da montagem, respectivamente.

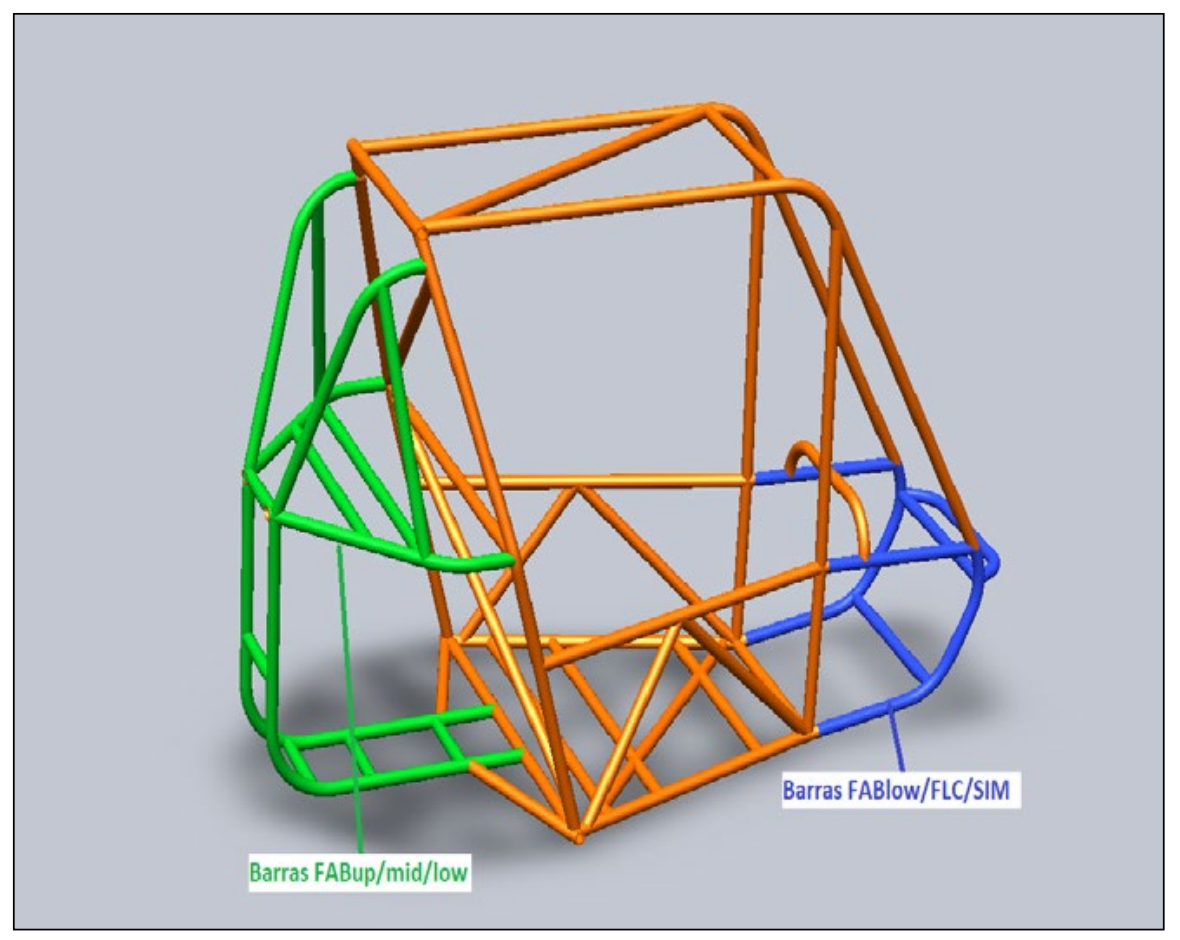

Fonte: Dos Autores (2020). 
Nesse mesmo ponto ocorre a modificação da suspensão, onde os amortecedores dianteiros tem seus pontos de fixação elevados, porém ainda continuarão alocados na balança inferior. A direção passará por modificações em seu local de fixação, sendo necessária a fixação na extremidade dianteira, ainda dentro do chassis do veículo. O freio também sofre alteração de posição, tendo uma elevação no seu ponto de fixação e, da mesma forma que o setor de direção, será levado mais à frente. Todo o sistema passaria a trabalhar integralmente, onde a potência será transmitida igualitariamente entre as 4 rodas. Para a passagem do eixo da parte traseira até a dianteira do veículo, será construído acima do assoalho, um receptáculo com dimensões ligeiramente superiores ao eixo, para que seja mantida a segurança do piloto. A Figura 5 permite a visualização do sistema proposto. Soma-se a proposta 1, o sistema de travamento dos eixos traseiros por meio de pinças e discos de freios individuais para cada ponta de eixo do veículo. Em ambas as situações em que o sistema simples de bloqueio e o sistema de bloqueio mecânico das rodas traseiras, agregam uma grande massa ao Baja, e somado ao fator baixa motorização, esta proposta não é viável para aplicação.

Figura 5 - Perspectiva proposta 1.

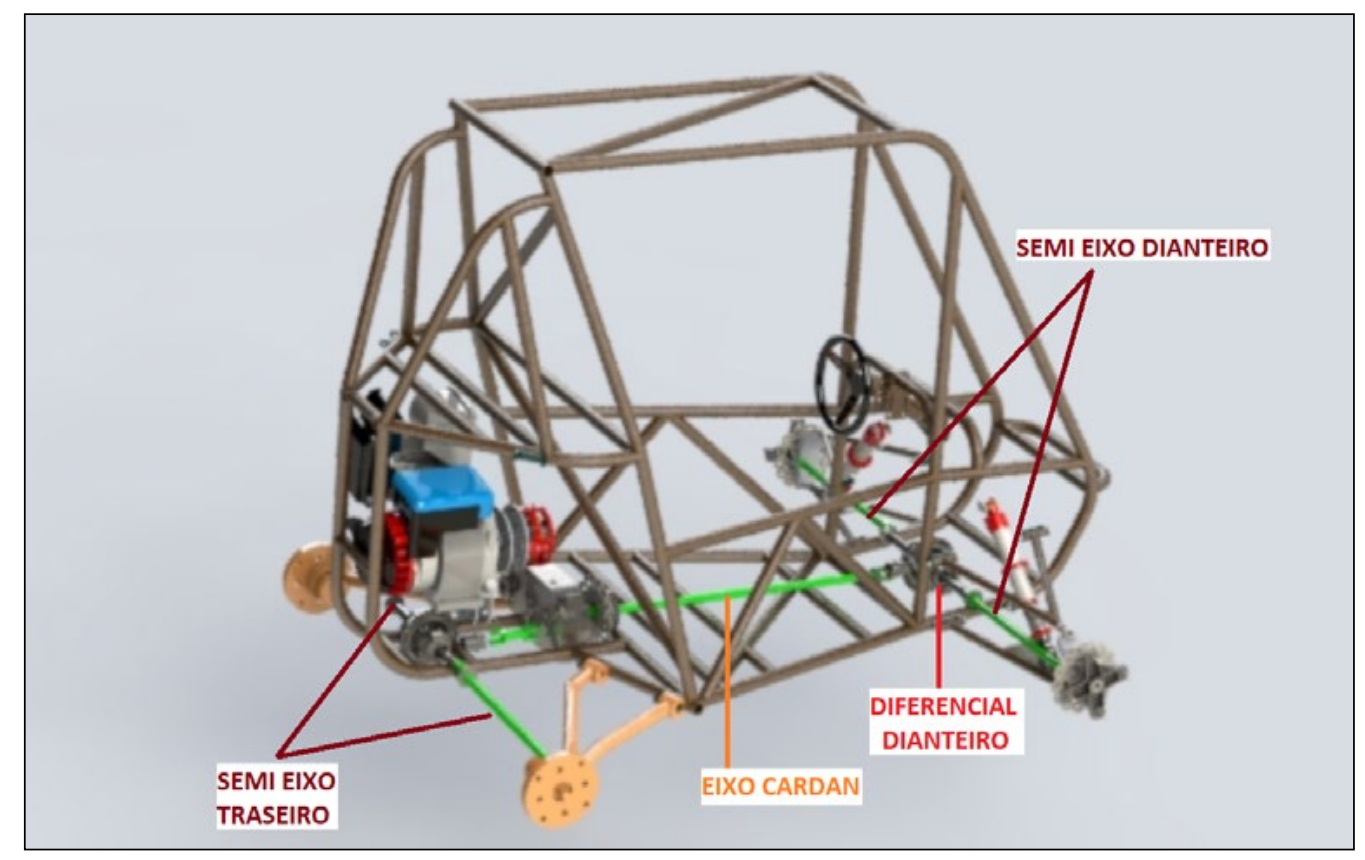

Fonte: Dos Autores (2020). 


\subsection{PROPOSTA 2}

Também com um sistema AWD, consiste em modificar a construção do modelo de caixa redutora utilizada atualmente no veículo, dimensionada por Weinandts (2019), onde a mesma passaria a contar com duas saídas de torque, uma para as rodas traseiras e outra para alimentar o eixo acoplado ao diferencial dianteiro, este, por sua vez, responsável por transmitir o torque para as rodas dianteiras através do eixo cardan. Essa proposta tem como objetivo criar uma adequação na caixa sem que a mesma perca sua relação atual de 7,84:1. As alterações sofridas nos componentes dianteiros serão da mesma intensidade que o exemplificado na proposta 01 , visto que os diferenciais utilizados em ambas serão iguais. A fixação do motor, bem como da caixa de transmissão, serão modificadas, para que seja possível manter a transmissão do torque para as rodas dianteiras o mais próximo possível do centro geométrico do veículo, visando uma melhor distribuição de massa, consequentemente o centro de gravidade do veículo não sofrerá alteração significativa. Um exemplo da proposta 02 é apresentado na Figura 6.

Figura 6 - Perspectiva da proposta 2.

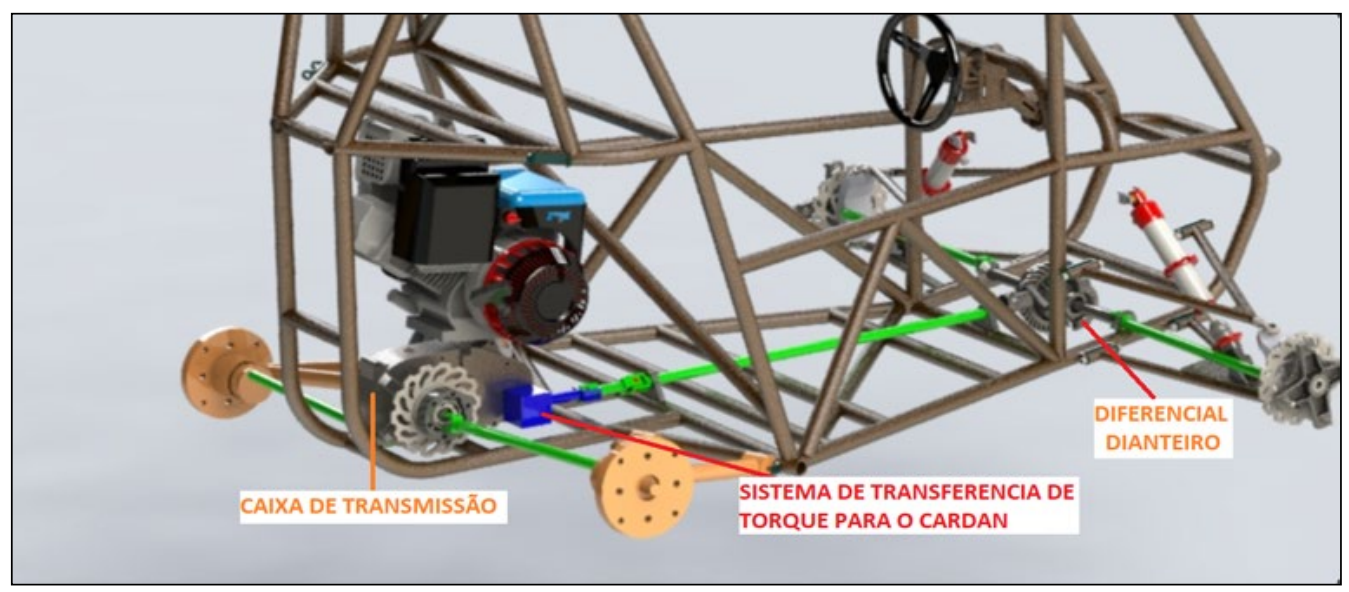

Fonte: Dos Autores (2020).

\subsection{PROPOSTA 3}

A aplicação do 4WD ficaria por conta da implementação do diferencial traseiro com bloqueio integral e diferencial dianteiro sem bloqueio, pois em competições o arrasto das rodas dianteiras seria menor, facilitando a manobrabilidade durante o esterçamento do volante, minimizando a perda de potência do subsistema em uma retomada. Diferente da proposta 2, o sistema 4 WD é responsável por integrar o sistema traseiro com o dianteiro, e esta seleção será feita através de um mecanismo de alavanca dentro do habitáculo, 
onde o piloto pode fazer a seleção desta transmissão, quando as capacidades do sistema $4 \times 2$ não forem suficientes para transpor o obstáculo proposto pelo comitê organizador do evento.

A equipe dentro da proposta 3 levantou duas possibilidades de montagem para a mesma configuração do sistema.

1. Acionamento por embreagem: Com o piloto dentro do habitáculo fazendo o acionamento da alavanca de comutação semelhante ao mecanismo de embreagem dos carros de rua atuais, onde o desligamento/acionamento do torque ao eixo é feito através de um conjunto de discos de fricção conforme Figura 7. Este método necessita a implementação de suportes para a fixação dos discos e estará suscetível a agressão de água e pó ao sistema.

2. Acionamento por garfo: $\mathrm{O}$ acionamento da alavanca de seleção de transmissão feita pelo piloto é semelhante ao ponto 1 da proposta 3, mas em vez de haver um mecanismo de platô e disco exposto às intempéries da competição, com o deslocamento do curso da alavanca, irá diretamente dentro da caixa de transmissão, onde um garfo seletor apoiado sobre uma luva deslizante ao eixo motriz fará esta ponte, transmitindo o torque. A Figura 7 representa o local da implementação do garfo seletor junto a caixa de transmissão, este sistema está mais próximo das possibilidades construtivas da equipe, dada a sua confiabilidade e custos.

Para a implementação destas propostas, necessita-se adicionar um par de engrenagens cônicas à caixa de transmissão atual.

Figura 7 - Perspectiva traseira proposta por embreagem da proposta 3.1.

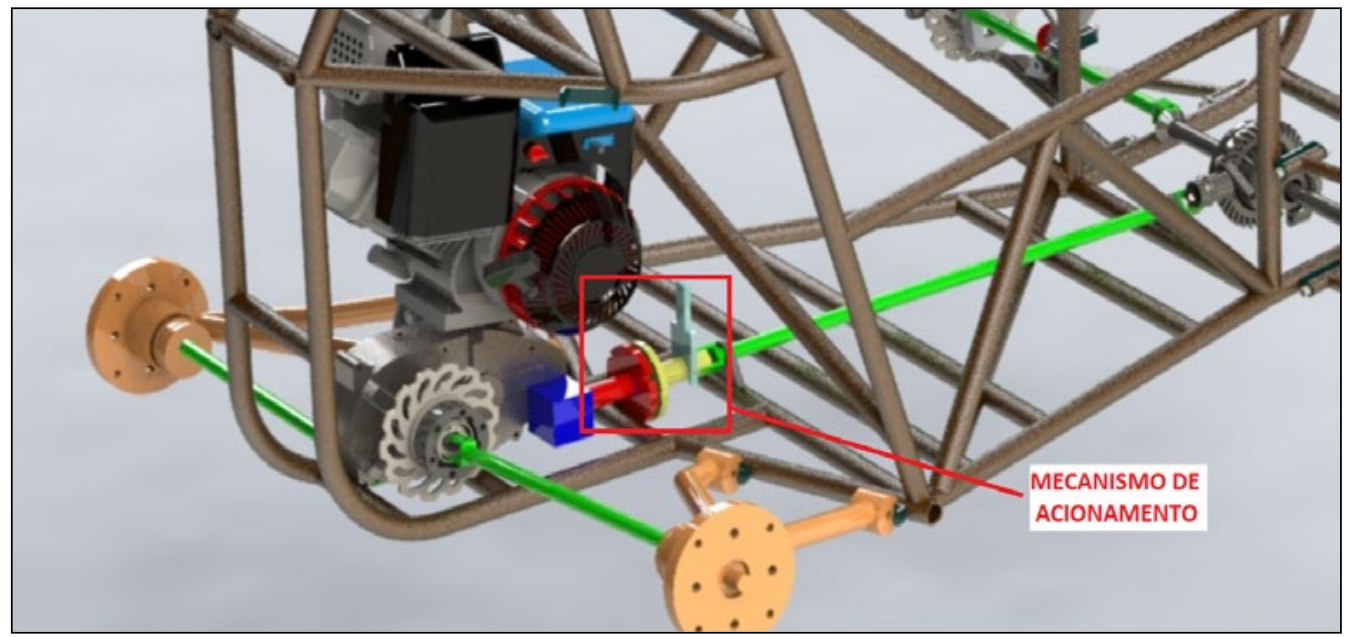

Fonte: Dos Autores (2020). 
Figura 8 - Perspectiva traseira proposta por embreagem da proposta 3.2.

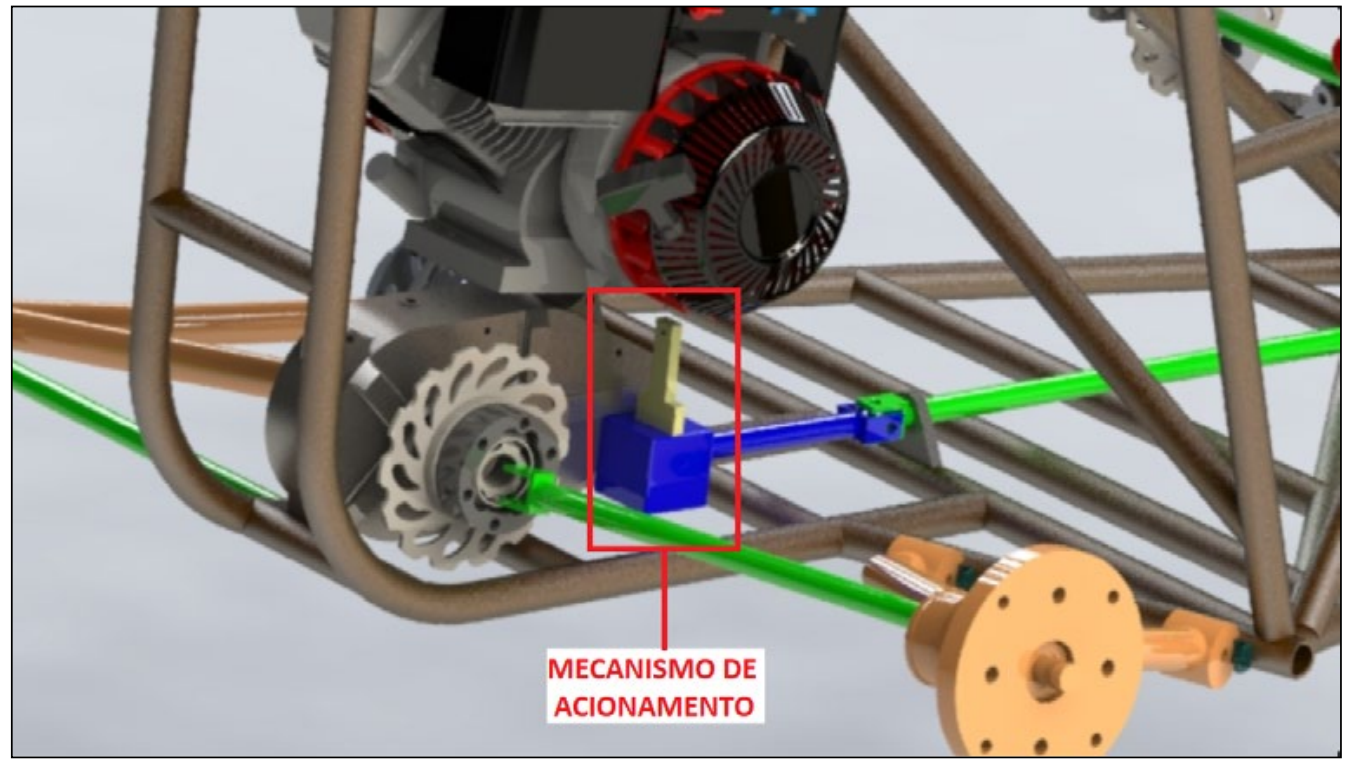

Fonte: Dos Autores (2020).

\subsection{PROPOSTA 4}

A quarta e última proposta que a equipe Baja Univates propõe é a implementação do sistema de transmissão hidráulica. Esta proposta visa diminuir a massa em comparação ao sistema da proposta 1. A utilização de fluidos incompreensíveis, tubulações de rede central rígida responsáveis pela interligação da bomba acoplada a CVT (Continuously Variable Transmission) do Baja para um sistema secundário de tubulações de material flexível, responsáveis por alimentar em cada uma das rodas, um mecanismo que se assemelha a um conversor de torque. Este sistema de conversão de torque tem sua peculiaridade de trabalhar junto à suspensão do veículo através das linhas de fluido flexíveis. Este sistema, por apresentar maior complexidade na confecção/aquisição dos conversores de torque e a bomba de alimentação central do sistema, agrega um alto valor ao protótipo. Outro fator a considerar é o aquecimento do fluído quando comprimido, a instalação de trocadores de calor ao sistema central e o uso do suporte de armazenamento elétrico limitado para fazer a ventilação forçada, pesa negativamente na escolha do sistema $4 \times 4$ acionado através de um sistema hidráulico.

Para a seleção da melhor proposta foi efetuada uma matriz de decisão, conforme apresentado por Norton (2011). O método consiste em selecionar a melhor alternativa pela determinação da maior média ponderada das notas após uma análise técnica. 
Esta metodologia auxilia quanto a melhor alternativa ao forçar o projetista a considerar uma ampla variedade de fatores de forma esquemática. Na matriz de decisão a primeira linha da tabela é reservada para os critérios de avaliação das propostas, enquanto que a segunda linha deve trazer o peso de cada um destes critérios. A primeira coluna são informados as propostas aos quais devem se atribuir notas. Todas as soluções propostas devem ser julgadas segundo cada parâmetro que devem ser definidos a partir das necessidades do problema inicial. No corpo da matriz são sinalizados as notas relacionando os critérios com as propostas estabelecidas. A escala de notas para fácil manipulação vão do intervalo de: zero a dez pontos.

Os critérios de seleção foram: custos, manutenção, adaptação, construção e provas. A Tabela 01 apresenta os resultados em função de cada proposta elaborada anteriormente.

Tabela 01 - Matriz de Decisão.

\begin{tabular}{|c|c|c|c|c|c|c|}
\hline & Custo & Manutenção & Adaptação & Construção & Provas & Rank \\
\hline Peso & 0,26 & 0,20 & 0,16 & 0,16 & 0,26 & 1,00 \\
\hline $\begin{array}{l}\text { Dois diferenciais } \\
\text { (Dianteiro } \bullet \\
\text { Traseiro),com } \\
\text { modelo de caixa de } \\
\text { redução atual. }\end{array}$ & 7 & 4 & 6 & 7 & 8 & 6,5 \\
\hline $\begin{array}{l}\text { Um diferencial } \\
\text { dianteiro, com } \\
\text { modificação na caixa } \\
\text { de redução. }\end{array}$ & 8 & 9 & 8 & 8 & 8 & 8,2 \\
\hline $\begin{array}{l}\text { Um diferencial } \\
\text { dlantelro, com } \\
\text { modificação na caixa } \\
\text { de reduçăo e } \\
\text { possibilidade de } \\
\text { engate do } \\
\text { mecanismo. }\end{array}$ & 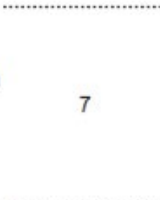 & 8 & 6 & 6 & 9 & 7,4 \\
\hline $\begin{array}{c}\text { Sistema de atuação } \\
\text { totalmente } \\
\text { hidráulico, para as } \\
\text { quatro rodas do } \\
\text { yeiculo }\end{array}$ & 4 & 6 & 4 & 5 & 2 & 4,05 \\
\hline & $\begin{array}{l}0=\text { mais caro } \\
10=\text { mais barato }\end{array}$ & $\begin{array}{l}0=\text { menos eficiente } \\
10=\text { mais eficiente }\end{array}$ & $\begin{array}{l}\text { Le } \\
0=\text { menos eficiente } \\
10=\text { mais eficiente }\end{array}$ & $\begin{array}{l}0=\text { menos eficiente } \\
0=\text { mais eficiente } \\
10 \text {. }\end{array}$ & $\begin{array}{l}0=\text { menos eficiente } \\
10=\text { mais eficiente }\end{array}$ & $\begin{array}{l}0=\text { menos eficiente } \\
10=\text { mais eficiente }\end{array}$ \\
\hline
\end{tabular}

Fonte: Dos Autores 2020.

Com base nos critérios pré-estabelecidos, e as notas atribuídas a cada um, com base nos autores citados anteriormente, a seleção, segundo a matriz de decisão, ficou com a segunda proposta, a qual obteve melhor desempenho em comparação às demais, alcançando uma nota de 8,2 no ranking. Onde o custo de adequação é favorável, a manutenção das peças é baixa e de fácil reposição, devido aos modelos de componentes selecionados, a adaptação e construção dos componentes para o veículo tipo BAJA SAE é mais sucinta quando 
comparada com as demais propostas e o desempenho em provas dinâmicas é adequado à proposta.

\section{CONCLUSÃO}

Através da matriz de decisão, foi observado que a proposta 4 - sistema por transmissão hidráulica, oferece maior grau de liberdade para atuação da suspensão e direção, mas em contrapartida, baixa velocidade final, elevado custo de fabricação e inclusão de sistemas termodinâmicos, dificultando a implementação desta proposta no momento.

Já a proposta 3 - sistema transmissão $4 \mathrm{WD}$, onde as construções dos modelos descritos vem de encontro com a fabricação da maioria dos veículos utilitários e off-road do mundo. Este modelo oferece benefícios na distribuição do torque disponível do motor, sendo que esta distribuição vem em momentos em que o piloto aciona o mecanismo do eixo que passa junto ao assoalho do habitáculo em momentos mais críticos de uso. Como a utilização do sistema necessita fazer grandes modificações na caixa atual, e associação de componentes de acionamento ao sistema, a equipe deixa a construção desta proposta como segunda opção.

A proposta 1 - Tração integral AWD com a utilização de dois diferenciais, tem a necessidade de fazer a fixação do motor e caixa no eixo perpendicular a linha de rodagem do veículo, possibilitando a utilização da caixa atual da equipe. O problema que a equipe encontra é a agregação de massa ao protótipo.

Com os resultados apresentados na matriz de decisão, a construção em um primeiro momento é na configuração da proposta 2 - Tração integral AWD com diferencial frontal e o traseiro sendo mantido conectado à caixa atual no sistema em modo de bloqueio. Com esta configuração, por mais que tenha de ser realizadas algumas alterações na caixa de transmissão, a equipe terá um menor investimento inicial para a entrega do protótipo. $\mathrm{O}$ sistema com diferencial frontal oferece uma vantagem em relação ao bloqueado, pois o esterçamento do sistema é facilitado com o livre rolamento de cada roda e conforme o raio de curva é diminuído ou aumentado.

\section{REFERÊNCIAS}

BAJA NACIONAL. SAE Brasil, São Paulo, SP. Disponível em: https://saebrasil.org. br/programas-estudantis/baja-sae-brasil. Acesso em: 25/01/2021.

BERGOLI, Bruno Accorsi. ESTUDO DE APLICAÇÃO E ANÁLISE DE TENSÕES EM UM DIFERENCIAL DE UM VEÍCULO BAJA. 2019. 57 f. TCC (Graduação) Curso de Engenharia Mecânica, Universidade Caxias do Sul, Bento Gonçalves, 2019. Disponível em: https://repositorio.ucs.br/xmlui/bitstream/handle/11338/5772/ TCC $\% 20$ Bruno $\% 20$ Accorsi $\% 20$ Bergoli.pdf?sequence=1\&isAllowed=y. Acesso em: 12 set. 2020. 
GRAHAM, I. How Thinks Work: Cars, bikes, trains and other land machines. 1. ed. New York: Grisewood \& Dempsey Inc, 1993.

GREWAL, Kawaldeep. Vehicle Differentials. 2011. Disponível em: https:/ / people. eecs.berkeley.edu/ sequin/CS285/2011_REPORTS/CS285\%20final\%20paper_ Kawaldeep.pdf. Acesso em: 15 set. 2019.

NORTON, Robert L. Machine design: an integrated approach. 4. ed. Boston: Prentice Hall, 2011.

SOBRAL, P. H. B. Projeto de um diferencial para veículo Baja SAE. 2015. Trabalho de conclusão de curso (Bacharelado em Engenharia Mecânica) Universidade de Brasília. Brasília, 2015. Disponível em: https:/ / www.bdm.unb.br/ bitstream/10483/13101/1/2015_PedroHenriqueBragaSobral.pdf. Acesso em: 10 set. 2020 .

VEERANJANEYULU, C.; BABU, U. H. Design and structural analysis of differential Gear box at different loads, International Journal of Advanced Engineering Research and Studies, Ongole, v. 1, n. 2, p. 65-69, mar. 2012. Disponível em: http:/ / citeseerx.ist.psu.edu/viewdoc/download?doi=10.1.1.466.5033\&rep=rep1\&type=pdf. Acesso em: 10 set. 2020.

WIENANDTS, Luis Felipe Radaelli. DIMENSIONAMENTO DO SISTEMA DE TRANSMISSÃO MECÂNICA PARA O VEÍCULO BAJA UNIVATES. 2019. 106 f. TCC (Graduação) - Curso de Engenharia Mecânica, Univates - Universidade do Vale do Taquari, Lajeado, 2019. Disponível em: https:/ / www.univates.br/bdu/ bitstream/10737/2740/1/2019LuisFelipeRadaelliWienandts.pdf. Acesso em: 12 set. 2020 . 